\title{
BMJ Open Near-normoglycaemia and development of neuropathy: a 24-year prospective study from diagnosis of type 1 diabetes
}

\author{
Dan Ziegler, ${ }^{1,2}$ Margarete Behler, ${ }^{1}$ Maria Schroers-Teuber, ${ }^{1}$ Michael Roden ${ }^{1,2}$
}

To cite: Ziegler D, Behler M, Schroers-Teuber M, et al. Near-normoglycaemia and development of neuropathy: a 24-year prospective study from diagnosis of type 1 diabetes. BMJ Open 2015;5 e006559. doi:10.1136/ bmjopen-2014-006559

- Prepublication history for this paper is available online. To view these files please visit the journal online (http://dx.doi.org/10.1136/ bmjopen-2014-006559).

Received 5 September 2014 Revised 12 March 2015 Accepted 18 March 2015

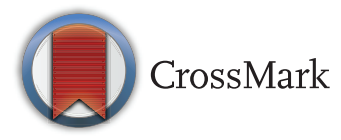

\footnotetext{
${ }^{1}$ Institute for Clinical Diabetology, German Diabetes Center at Heinrich Heine University, Leibniz Center for Diabetes Research, Düsseldorf, Germany

${ }^{2}$ Department of

Endocrinology and Diabetology, Medical Faculty, Heinrich Heine University, Düsseldorf, Germany
}

\section{Correspondence to} Professor Dan Ziegler; dan.ziegler@ddz.uniduesseldorf.de

\section{ABSTRACT}

Objective: Complete prevention of diabetic neuropathies has not been previously demonstrated. We sought to determine whether long-term nearnormoglycaemia maintained from the diagnosis of type 1 diabetes is associated with polyneuropathy and cardiac autonomic dysfunction.

Design: Prospective observational study over 24 years. Setting: Ambulatory care.

Participants: 32 newly diagnosed patients with type 1 diabetes aged $20.3 \pm 1.0$ years, duration of diabetes $2.7 \pm 0.3$ weeks.

Intervention: Insulin therapy according to standards of care.

\section{Primary and secondary outcome measures:}

Motor and sensory nerve conduction velocity (MNCV and SNCV), heart rate variability (HRV), and confirmed clinical polyneuropathy measured at 15 time points over 24 years and quantitative sensory testing (QST) determined over 20-22 years.

Results: 11 patients were well controlled over 24 years with mean glycated haemoglobin $(\mathrm{HbA} 1 \mathrm{c})<7.0 \%$ (6.5 $\pm 0.1 \%$; group 1), whereas 21 patients were poorly controlled (mean $\mathrm{HbA} 1 \mathrm{C} \geq 7.0 \%$ : 8.3 $\pm 0.2 \%$; group 2). After 24 years, MNCV was faster in group 1 versus group 2 in the median $(55.5 \pm 1.6$ vs $48.9 \pm 1.6 \mathrm{~m} / \mathrm{s})$, ulnar $(56.5$ \pm 1.5 vs $49.3 \pm 1.7 \mathrm{~m} / \mathrm{s})$ and peroneal nerve $(44.7 \pm 1.6$ vs $36.8 \pm 2.5 \mathrm{~m} / \mathrm{s}$ ), while SNCV was faster in the median $(53.6 \pm 1.6$ vs $45.5 \pm 2.8 \mathrm{~m} / \mathrm{s})$, ulnar $(54.7 \pm 1.8$ vs 43.0 $\pm 3.9 \mathrm{~m} / \mathrm{s})$, and sural nerve $(44.5 \pm 1.8$ vs $35.5 \pm 2.6 \mathrm{~m} / \mathrm{s}$; all $\mathrm{p}<0.05)$. The annual decline in peroneal MNCV and sural SNCV in group 1 was sixfold and threefold faster in group 2 than in group 1, respectively. Likewise, impairment in QST and HRV developed at faster rates in group 2. After 24 years, $64 \%$ of patients in group 2, but none in group 1, developed confirmed clinical polyneuropathy.

Conclusions: Near-normoglycaemia maintained from the diagnosis of type 1 diabetes over 24 years was associated with a complete prevention of the decline in hyperglycaemia-related peripheral and autonomic nerve function, and development of confirmed clinical polyneuropathy.

\section{INTRODUCTION}

Approximately one-third of patients with diabetes are affected by diabetic sensorimotor

\section{Strengths and limitations of this study}

This prospective observational study conducted over 24 years evaluated whether long-term nearnormoglycaemia maintained from the diagnosis of type 1 diabetes prevents polyneuropathy and cardiac autonomic dysfunction.

- Prospective assessment of neuropathy included detailed quantitative assessment of nerve function rather than nerve structure, since the latter became quantifiable only recently.

- The results of this study may provide a rationale for the design of future long-term clinical trials aimed at prevention of diabetic neuropathy.

- Allocation of patients to two groups markedly differing with regard to the degree of glycaemic control could only be done post hoc, and the small study sample may be a source of bias.

polyneuropathy (DSPN), which leads to considerable morbidity due to neuropathic pain and foot ulcers, while cardiovascular autonomic neuropathy (CAN) is associated with a threefold increased risk of mortality. ${ }^{12}$ Chronic cumulative glycaemic exposure is a major causative, yet modifiable, factor in the development and progression of diabetic microvascular complications, ${ }^{3}$ but it accounts for only about one-third of the variability of the severity of complications in the diabetic general population. ${ }^{4}$ The Diabetes Control and Complications Trial/Epidemiology of Diabetes Interventions and Complications (DCCT/ EDIC) confirmed that glycaemic control is a robust predictor of DSPN and CAN in patients with type 1 diabetes. ${ }^{5}$ The persistent long-term favourable effects shown during EDIC of the prior intensive insulin therapy (IT) compared with conventional insulin therapy (CT) during DCCT on diabetic microvascular complications have been termed 'metabolic memory'. 7 In the DCCT, glycated haemoglobin (HbA1c) explained $92 \%$ of the difference in risk of neuropathy between IT and CT.

However, DCCT/EDIC also revealed that for most patients with type 1 diabetes, 
current strategies for optimising glucose control are insufficient to fully prevent or delay the development of DSPN and CAN. ${ }^{5} 7$ In fact, $25 \%$ of the former IT group and $35 \%$ of those in the former CT group had confirmed DSPN by 13-14 years of EDIC follow-up, ${ }^{9}$ while the corresponding rates for CAN were $29 \%$ and $35 \%$, respectively. ${ }^{10}$ The mean HbAlc levels at EDIC years 1314 were $7.8 \%$ in each of the former insulin treatment groups. ${ }^{9}$ Although IT prevented diabetic neuropathy only to a modest degree, there is general agreement that IT targeting HbAlc levels $<7 \%$ should be implemented as early as possible in the course of type 1 diabetes. $^{5} 711$

On the basis of the DCCT/EDIC observations, it is conceivable that maintenance of the recommended HbA1c level $<7 \%$ in the long term from the time of diabetes onset could result in more effective prevention of neuropathy. However, detailed long-term prospective studies assessing the evolution of neuropathy from the diagnosis of type 1 diabetes onward are not available. The aim of the present study was to determine the longterm development of DSPN and CAN during nearnormoglycaemia compared with poor glycaemic control from the diagnosis of type 1 diabetes over the next 24 years by using a comprehensive array of measures to detect early large and small nerve fibre dysfunction in conjunction with the clinical assessment.

\section{METHODS}

\section{Patients}

Thirty-two inpatients with type 1 diabetes admitted to the clinical department of the German Diabetes Center at Heinrich Heine University, Düsseldorf, in $1985,{ }^{12}$ participated in this prospective observational study and were followed up for 24 years with outpatient visits at 3 months and 1, 2, 4, 5, 8, 10, 12, $14,16,18,20,22$ and 24 years following the baseline assessment. The study has been carried out in accordance with the principles of the Declaration of Helsinki as revised in 1983. Informed consent was obtained from all eligible patients after the procedures involved were fully explained. Inclusion criteria were age below 40 years, type 1 diabetes according to the National Diabetes Data Group classification, ${ }^{13}$ known diabetes duration of up to 2 months, and mean blood glucose $80-160 \mathrm{mg} / \mathrm{dL}$ at the baseline assessment. Exclusion criteria were causes of neuropathy other than diabetes, clinically relevant neurological diseases and use of medication with potential influence on nerve function. All patients underwent a standardised 1-week diabetes teaching programme.

To establish whether the development of neuropathy is related to the long-term degree of glycaemic control, patients were grouped according to their mean $\mathrm{HbAlc}$ levels during the 24 years of follow-up (excluding baseline $\mathrm{HbA1c}$ ), in line with the current recommendations by the American Diabetes Association. ${ }^{11}$ During the 24-year period, 11 patients had mean HbA1c levels within the recommended target $<7.0 \% \quad(<53.0 \mathrm{mmol} / \mathrm{mol} ; 6.5$ $\pm 0.1 \%(47.1 \pm 1.0 \mathrm{mmol} / \mathrm{mol})$; group 1$)$, whereas 21 patients had mean HbAlc levels $\geq 7.0 \%$ ( $\geq 53.0 \mathrm{mmol} /$ $\mathrm{mol} ; 8.3 \pm 0.2 \%(67.2 \pm 2.2 \mathrm{mmol} / \mathrm{mol})$; group 2$)$. Ten healthy subjects ( 5 men, age: $37.3 \pm 2.8$ years, height: 172 $\pm 3.2 \mathrm{~cm}$, weight: $72.9 \pm 3.5 \mathrm{~kg}$, body mass index, BMI: 24.5 $\left.\pm 0.9 \mathrm{~kg} / \mathrm{m}^{2}\right)$ served as controls for the nerve conduction studies. The clinical characteristics of the diabetic groups at baseline are shown in table 1 . There were no significant differences between the groups for any of the parameters listed. Compared with the controls, both diabetic groups were younger and group 2 had a lower BMI $(\mathrm{p}<0.05)$.

Table 1 Demographic and clinical characteristic of the patients at baseline

\begin{tabular}{|c|c|c|}
\hline & $\begin{array}{l}\text { Group } 1 \\
\text { HbA1c }<7.0 \%\end{array}$ & $\begin{array}{l}\text { Group } 2 \\
\text { HbA1c } \geq 7.0 \%\end{array}$ \\
\hline $\mathrm{n}$ & 11 & 21 \\
\hline Sex (male/female) & $7 / 4$ & $14 / 7$ \\
\hline Age (years) & $19.4 \pm 0.9$ & $20.8 \pm 1.4$ \\
\hline Height $(\mathrm{cm})$ & $175 \pm 2.2$ & $176 \pm 2.0$ \\
\hline Weight (kg) & $68.6 \pm 6.4$ & $64.0 \pm 3.1$ \\
\hline $\mathrm{BMI}\left(\mathrm{kg} / \mathrm{m}^{2}\right)$ & $21.9 \pm 1.7$ & $20.4 \pm 0.8$ \\
\hline Systolic blood pressure (mm Hg) & $127 \pm 7.0$ & $117 \pm 3.9$ \\
\hline Diastolic blood pressure (mm Hg) & $81.3 \pm 6.6$ & $69.4 \pm 3.9$ \\
\hline Duration of symptoms (weeks) ${ }^{\star}$ & $5.5 \pm 1.7$ & $6.7 \pm 2.3$ \\
\hline Duration of insulin treatment (weeks) & $2.6 \pm 0.5$ & $2.7 \pm 0.5$ \\
\hline Insulin dose (IU/day) & $28.3 \pm 5.1$ & $37.2 \pm 4.3$ \\
\hline HbA1c (\%) & $8.8 \pm 0.6$ & $9.1 \pm 0.3$ \\
\hline $\mathrm{HbA1c}(\mathrm{mmol} / \mathrm{mol})$ & $72.6 \pm 5.2$ & $76.5 \pm 2.9$ \\
\hline Mean blood glucose $(\mathrm{mg} / \mathrm{dL}) \dagger$ & $111 \pm 8.0$ & $121 \pm 4.2$ \\
\hline Islet cell antibody positive (\%) & 75 & 84 \\
\hline
\end{tabular}




\section{Electrophysiological tests}

Motor nerve conduction velocity (MNCV) was measured in the median, ulnar and peroneal nerves, while sensory nerve conduction velocity (SNCV) was determined in the median, ulnar and sural nerves at baseline, and during each subsequent visit at a skin temperature of $32^{\circ} \mathrm{C}-34^{\circ} \mathrm{C}$ using surface electrodes (EMG 2000 electromyograph, Schwarzer-Picker, Munich, Germany; Sapphire, Medelec, Woking, UK; VikingQuest EMG, Cardinal Health, Madison, Wisconsin, USA) as previously described. ${ }^{12}$

\section{Quantitative sensory testing}

Vibration perception threshold (VPT) was measured from the second year at the second metacarpal bone and medial malleolus using the method of limits (Vibrameter, Somedic, Stockholm). Thermal perception thresholds (TPT) to warm and cold stimuli were determined from the fourth year at the thenar eminence and dorsum of the foot using the method of limits (Marstock stimulator, Somedic, Stockholm, Sweden; Path-Tester; Tönnies, Germany; TSA II NeuroSensory Analyser, Medoc, Ramat Yishai, Israel) as previously reported. ${ }^{12} 14$

\section{Clinical examination and confirmed DSPN}

Neurological examination at baseline and each visit included assessment of neuropathic symptoms, vibration sensation using the Rydel-Seiffer tuning fork, thermal perception (tip therm, Brüggen, Germany), ankle reflexes, and pin-prick perception. Neuropathic deficits and symptoms were scored using the Neuropathy Disability Score (NDS) and the Neuropathy Symptom Score (NSS) ${ }^{15}$ Criteria for the definition of confirmed clinical DSPN included NDS $\geq 2$ and reduced peroneal MNCV and/or sural SNCV below the fifth centile and elevated malleolar VPT and/or warm TPT and/or cold TPT on the dorsum of the foot above the 95th centile of healthy subjects. ${ }^{12} 14$

\section{Heart rate variability}

Coefficient of variation (CV) of heart rate variability (HRV) during spontaneous breathing over 5 min was assessed from baseline and CV during deep breathing over $1 \mathrm{~min}$ was measured from the first year (NeurocardAnalyzer, Argustron, Mettmann, Germany; ProSciCard, CPS Medical, Wetzlar, Germany; NeuroDiag II, Dr Vetter, Baden-Baden, Germany; VariaCardio TF5 System, AMD Group, Buckinghamshire, UK) as previously described. ${ }^{12} 16$

The NCV, TPT and HRV parameters were measured in the same way using equipment from different manufacturers and were comparable throughout the study.

\section{Retinal assessment}

Colour retinal photographs were produced by a CR3-45NM non-mydriatic retinal camera (Canon, Tokyo, Japan) and were judged by an experienced examiner.

\section{Laboratory methods}

HbA1c was measured at baseline and each visit using the high-performance liquid chromatography technique (Diamat, Bio-Rad, Munich, Germany). The examiners were not blinded to the HbAlc results at the individual time points. Capillary blood glucose was measured by a hexokinase-based method (ACP 5040 autoanalyzer, Eppendorf, Hamburg, Germany; Cobas C 311 analyzer, Roche Diagnostics, Mannheim, Germany). Albuminuria was measured in $12 \mathrm{~h}$ urine samples using the immunonephelometric technique (Array Protein System, Beckman, Fullerton, California, USA) or turbidimetric method (Cobas C 311 analyzer, Roche Diagnostics, Mannheim, Germany) with a normal range: $<20 \mu \mathrm{g} / \mathrm{min}$. Islet cell antibodies were measured by indirect immunofluorescence using snap frozen, unfixed human pancreatic sections of blood 0 donors. ${ }^{17}$

\section{Statistical analysis}

Continuous data were expressed as mean \pm SEM. Categorical data were given as absolute or relative frequencies. Post hoc comparisons of study end points between the two groups with mean HbA1c $<7.0 \%$ and mean HbAlc $\geq 7.0 \%$, from 3 months to 24 years of the study, were performed using the t test for two independent samples without missing data imputation. The level of significance was set at $\alpha=0.05$.

\section{RESULTS}

\section{Glycaemic control and microvascular complications}

Insulin therapy was initiated in all patients with either subcutaneous or intravenous application of human or porcine regular insulins. After correction of the initial metabolic derangement, patients were treated with multiple daily insulin injections according to standards of care throughout the study. During the study, 2 patients in each group switched to continuous subcutaneous insulin infusion. The mean HbAlc levels in the two groups studied are shown in figure 1A. HbAlc decreased in group 1, from $8.8 \pm 0.6 \%$ at baseline to a mean of $6.5 \pm 0.1 \%$ throughout the 14 subsequent outpatient visits; in group 2, HbA1c decreased from 9.1 $\pm 0.3 \%$ to $8.3 \pm 0.2 \%$. The daily insulin dose in groups 1 and 2 was $28.3 \pm 5.1$ and $37.2 \pm 4.3 \mathrm{IU} /$ day at baseline, $49.6 \pm 5.1$ and $68.3 \pm 4.7 \mathrm{IU} /$ day $(\mathrm{p}<0.05)$ at 10 years, 49.7 \pm 5.7 and $64.7 \pm 6.8 \mathrm{IU} /$ day at 20 years, and $52.1 \pm 6.4$ and $69.3 \pm 8.3 \mathrm{IU} /$ day at 24 years, respectively. The number of cigarettes smoked per day in groups 1 and 2 was 6.1 \pm 2.6 and $7.7 \pm 3.3$ at 4 years, $9.5 \pm 3.0$ and $9.2 \pm 3.7$ at 10 years, $6.1 \pm 2.7$ and $6.5 \pm 3.5$ at 20 years, and $3.5 \pm 2.6$ and $6.9 \pm 4.3$ at 24 years, respectively.

At baseline, none of the patients had nephropathy or retinopathy. The percentages of patients with microalbuminuria/macroalbuminuria in groups 1 and 2 were $0 \%$ and $20 \%$ at 12 years, and $0 \%$ and $43 \%$ at 24 years, respectively. The percentages of patients with retinopathy 
A

Group 1: Mean HbA1c $<7.0 \%(6.5 \pm 0.1 \%)$

Group 2: Mean HbA1c $\geq 7.0 \%(8.3 \pm 0.2 \%)$

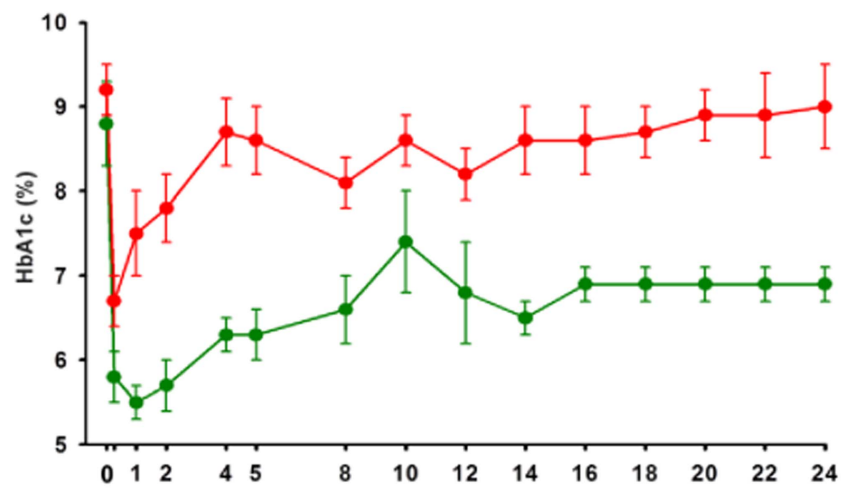

Group 1: Mean HbA1c $<7.0 \%(6.5 \pm 0.1 \%$

Group 2: Mean HbA1c $\geq 7.0 \%(8.3 \pm 0.2 \%)$

Control Group

B
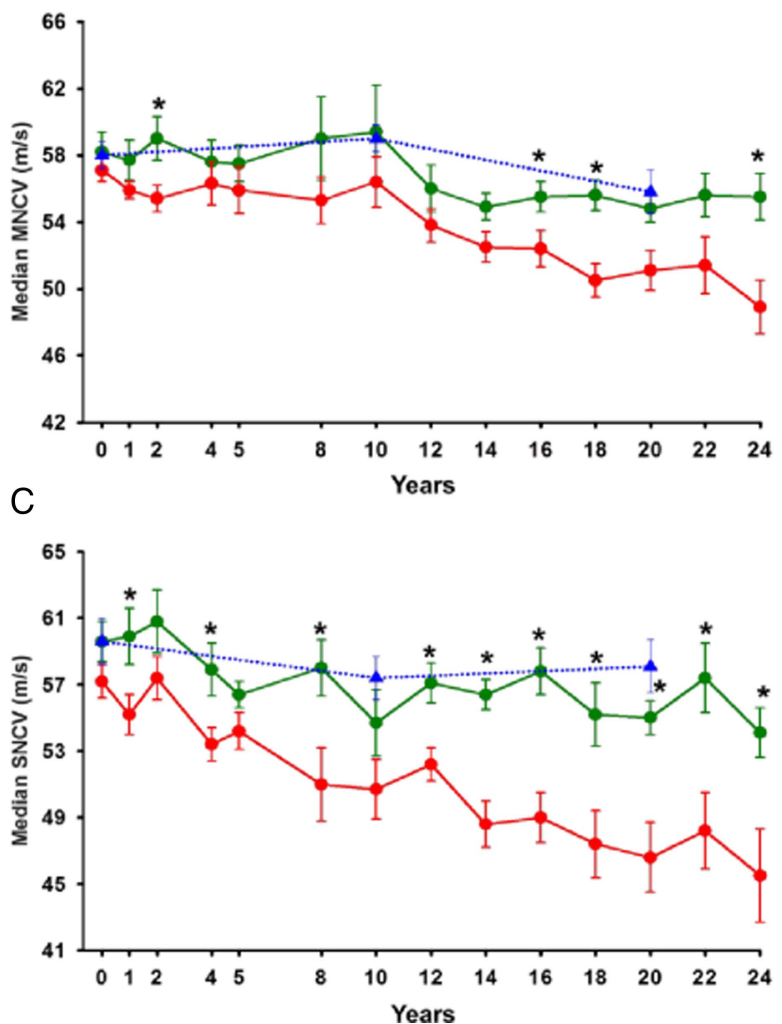

C
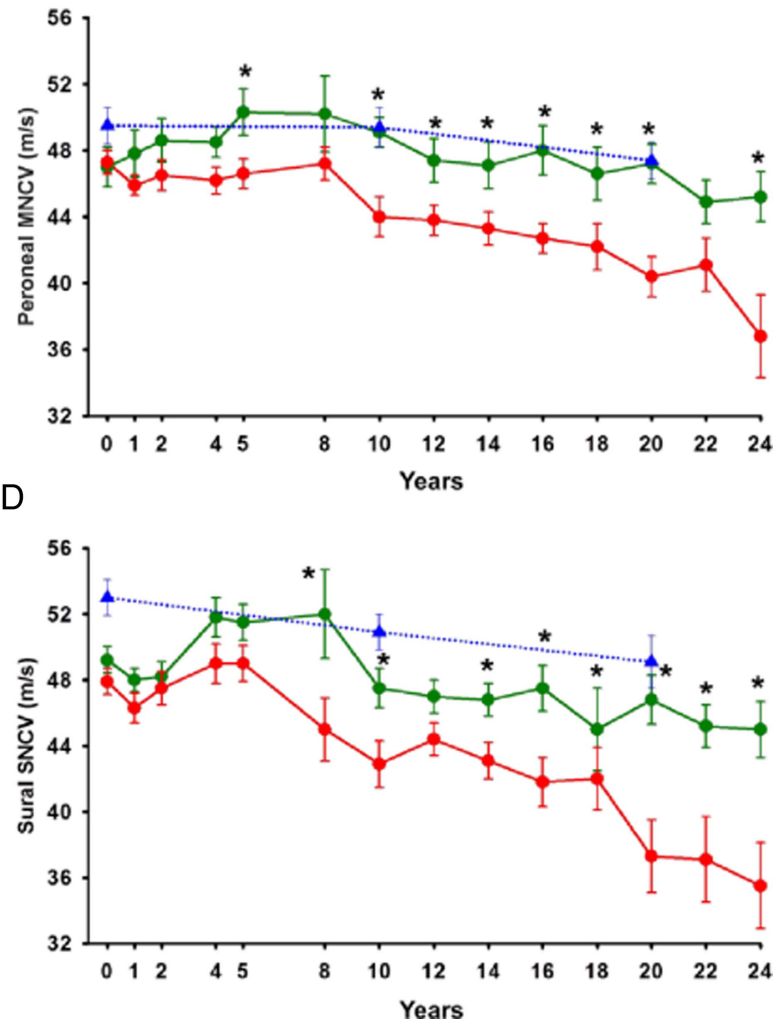

Figure $1 \mathrm{HbA1c}$ levels (A), median MNCV (B), peroneal MNCV (C), median SNCV (D), and sural SNCV (E) over 24 years in group 1 (mean $\mathrm{HbA} 1 \mathrm{c}<7.0 \% ; n=11$ ) and group 2 (mean $\mathrm{HbA} 1 \mathrm{c} \geq 7.0 \% ; n=21$ ), and healthy control subjects ( $n=11$ ) over 20 years. ${ }^{*} p<0.05$ for group 1 versus group 2 (HbA1c, glycated haemoglobin; MNCV, motor nerve conduction velocity; SNCV, sensory nerve conduction velocity).

in groups 1 and 2 were $0 \%$ and $17 \%$ at 12 years, and $10 \%$ and $55 \%$ at 24 years, respectively.

The most frequently used medication at 24 years in groups 1 and 2 included-ACE inhibitors/AT1 blockers: $33 \%$ and $55 \%$; $\beta$-blockers: $22 \%$ and $36 \%$; diuretics: $0 \%$ and $36 \%$; calcium channel blockers: $0 \%$ and $27 \%$; statins: $33 \%$ and $45 \%$ and ASS: $0 \%$ and $27 \%$ of the patients, respectively.
Peripheral and cardiac autonomic nerve function

The course of median and peroneal MNCV, and median and sural SNCV in the two diabetic groups and controls is illustrated in figure 1B-E. No significant differences in $\mathrm{NCV}$ between the diabetic groups were noted at baseline. Median MNCV was faster in group 1 than group 2 at 2, 16, 18 and 24 years (figure 1B), while for peroneal MNCV this was the case at 5, 10-20, and 24 years 


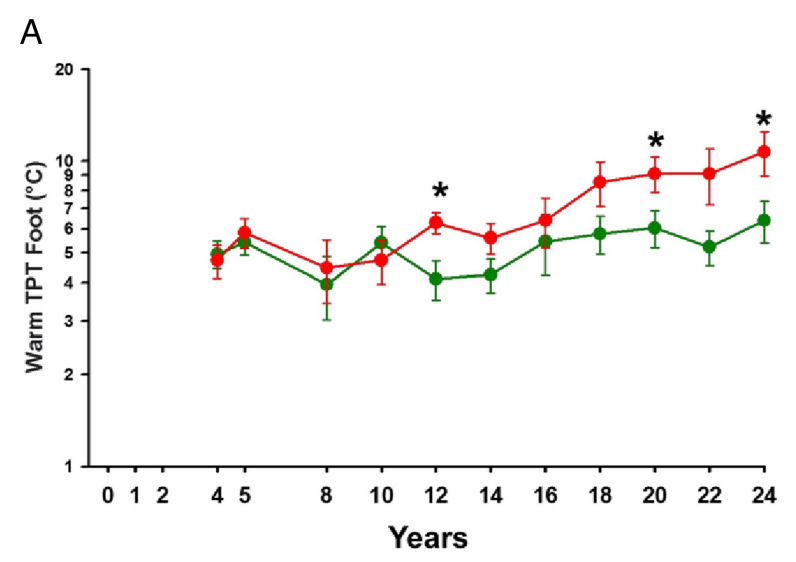

Group 1: Mean HbA1c $<7.0 \%(6.5 \pm 0.1 \%)$

B
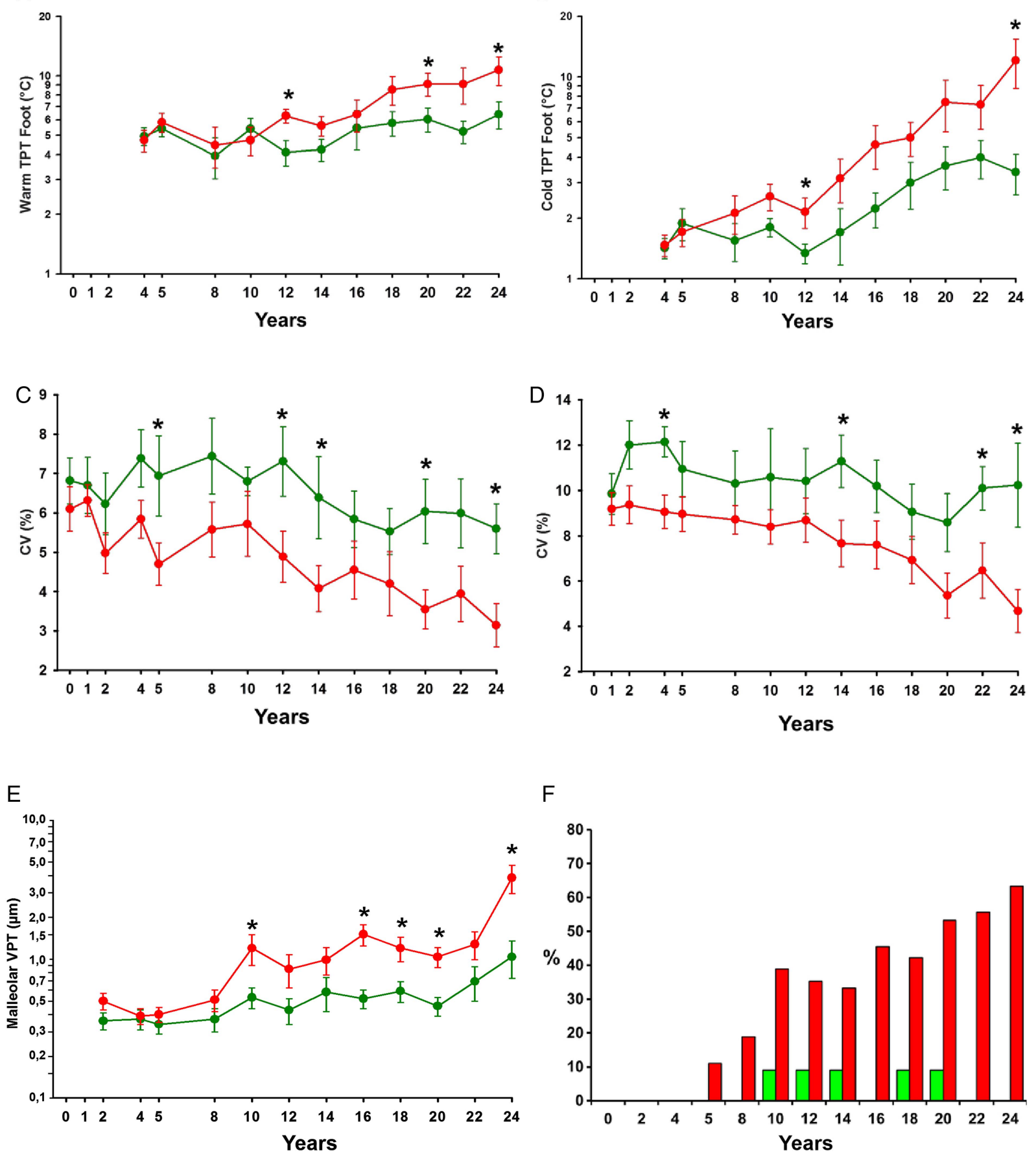

Figure 2 Warm TPT (A) and cold TPT (B) on the dorsum of the foot from the fourth year, CV of R-R intervals at rest over 24 years (C) and CV during deep breathing from the first year (D), VPT from the second year (E), and cumulative prevalence of confirmed clinical DSPN over 24 years $(F)$. ${ }^{*} p<0.05$ for group 1 versus group 2 (HbA1c, glycated haemoglobin; CV, coefficient of variation; DSPN, diabetic sensorimotor polyneuropathy;TPT, thermal perception threshold; VPT, vibration perception threshold).

(figure 1C; all $\mathrm{p}<0.05$ ). Median SNCV was higher in group 1 than group 2 at $1,4,8$ and 12-24 years (figure 1D), while accordingly sural SNCV was higher at 8,10 and $14-24$ years (figure $1 \mathrm{E}$; all $\mathrm{p}<0.05$ ). NCV in the four nerves studied after 10 and 20 years did not differ between group 1 and the healthy control group.
The course of quantitative sensory testing (QST), HRV and confirmed DSPN is shown in figure 2. No significant differences between the groups in these measures were observed at the time of initial assessment. Thereafter, warm TPT was elevated in group 2 versus group 1 at 12, 20 and 24 years (figure 2A), while cold 
TPT was increased in group 2 versus group 1 at 12 and 24 years (figure 2B; all $\mathrm{p}<0.05$ ). CV of $\mathrm{R}-\mathrm{R}$ intervals at rest was better in group 1 versus group 2 at 5, 12, 14, 20 and 24 years (figure 2C), while CV during deep breathing was better in group 1 versus group 2 at 4, 14, 22 and 24 years (figure 2D;b; all $\mathrm{p}<0.05$ ). Malleolar VPT was elevated in group 2 versus group 1 at 10, 16-20 and 24 years (figure $2 \mathrm{E}$; all $\mathrm{p}<0.05$ ). Confirmed DSPN was not present in either group up to 4 years. After 10, 16 and 24 years, cumulative prevalence of confirmed clinical DSPN in group 2 was $39 \%, 46 \%$ and $64 \%$, respectively, whereas in group 1, only a transient occurrence of one case, each meeting the criteria of confirmed clinical DSPN, was observed at 10-14, 18 and 20 years of follow-up (figure 2F).

The changes in the diabetic groups in NCV over 24 years, VPT over 22 years, TPT over 20 years, and CV of $\mathrm{HRV}$ at rest and during deep breathing over 24 and 23 years, respectively, as well as the changes in NCV in the control group over 20 years are listed in table 2 . The most pronounced decline in group 2 was noted for peroneal MNCV and sural SNCV which was approximately sixfold and threefold faster than in group 1 , respectively. SNGV declined slightly more rapidly $(0.85-1.08 \mathrm{~m} / \mathrm{s}$ / year) than MNCV $(0.60-1.04 \mathrm{~m} / \mathrm{s} /$ year $)$ in group 2 . The magnitude of decline in MNCV and SNCV over 20 years in group 1 was comparable to that seen in the control group. For the majority of the remaining measures, progression in group 2 was 2.5-fold to 13-fold faster than in group 1. The highest rate of deterioration in group 2 was noted for cold TPT on the foot and malleolar VPT.

The numbers of patients lost to follow-up at the individual time points in groups 1 and 2 varied; this was 2 and 3 at 5 years, 1 and 4 at 12 years, 1 and 6 at 20 years, and 2 and 10 at 24 years, respectively. Among these, two patients from group 2 died during follow-up, one woman from diabetic ketoacidosis after 12 years and one man supposedly from severe hypoglycaemia after

Table 2 Changes in MNCV and SNCV, VPT, TPT and CV of HRV during the study

\begin{tabular}{|c|c|c|c|c|c|}
\hline & $\begin{array}{l}\text { Group } \\
\text { (HbA1c) }\end{array}$ & $\begin{array}{l}\text { Absolute } \\
\text { change over } \\
24 \text { years }\end{array}$ & $\begin{array}{l}\text { Absolute } \\
\text { change per } \\
\text { year }\end{array}$ & $\begin{array}{l}\text { Per cent } \\
\text { change } \\
\text { over } 24 \text { years }\end{array}$ & $\begin{array}{l}\text { Per cent } \\
\text { change } \\
\text { per year }\end{array}$ \\
\hline \multirow[t]{3}{*}{ Median MNCV (m/s or \%) } & Control & $-2.2^{*}$ & -0.11 & $-3.8^{*}$ & -0.19 \\
\hline & Group $1(<7 \%)$ & -2.7 & -0.11 & -4.6 & -0.19 \\
\hline & Group $2(\geq 7 \%)$ & -8.2 & -0.34 & -14.4 & -0.60 \\
\hline \multirow[t]{3}{*}{ Ulnar MNCV (m/s or \%) } & Control & $-5.4^{*}$ & -0.27 & $-8.7^{\star}$ & -0.44 \\
\hline & Group $1(<7 \%)$ & -2.6 & -0.11 & -4.4 & -0.18 \\
\hline & Group $2(\geq 7 \%)$ & -11.5 & -0.48 & -18.9 & -0.79 \\
\hline \multirow[t]{3}{*}{ Peroneal MNCV (m/s or \%) } & Control & $-2.6^{*}$ & -0.13 & $-5.3^{\star}$ & -0.27 \\
\hline & Group $1(<7 \%)$ & -1.8 & -0.08 & -3.8 & -0.16 \\
\hline & Group 2 ( $\geq 7 \%)$ & -11.8 & -0.49 & -24.9 & -1.04 \\
\hline \multirow[t]{3}{*}{ Median SNCV (m/s or \%) } & Control & $-1.5^{\star}$ & -0.08 & $-2.5^{\star}$ & -0.13 \\
\hline & Group $1(<7 \%)$ & -5.5 & -0.23 & -9.2 & -0.38 \\
\hline & Group 2 ( $\geq 7 \%)$ & -11.7 & -0.49 & -20.5 & -0.85 \\
\hline \multirow[t]{3}{*}{ Ulnar SNCV (m/s or \%) } & Control & $0.4^{\star}$ & 0.02 & $0.7^{*}$ & 0.04 \\
\hline & Group 1 (<7\%) & -0.4 & -0.02 & -0.7 & -0.03 \\
\hline & Group 2 ( $\geq 7 \%)$ & -11.1 & -0.46 & -20.3 & -0.85 \\
\hline \multirow[t]{3}{*}{ Sural SNCV (m/s or \%) } & Control & $-4.8^{*}$ & -0.24 & $-9.1^{*}$ & -0.46 \\
\hline & Group 1 (<7\%) & -4.2 & -0.18 & -8.5 & -0.35 \\
\hline & Group 2 ( $\geq 7 \%)$ & -12.4 & -0.52 & -25.9 & -1.08 \\
\hline \multirow[t]{2}{*}{ Metacarpal VPT ( $\mu \mathrm{m}$ or \%) } & Group 1 (<7\%) & $0.04 \dagger$ & 0.002 & $16.7 \dagger$ & 0.76 \\
\hline & Group 2 ( $\geq 7 \%)$ & $0.24 \dagger$ & 0.01 & $114 \dagger$ & 5.18 \\
\hline \multirow[t]{2}{*}{ Malleolar VPT ( $\mu \mathrm{m}$ or \%) } & Group 1 (<7\%) & $0.47 \dagger$ & 0.02 & $162 \dagger$ & 7.36 \\
\hline & Group $2(\geq 7 \%)$ & $2.43 \dagger$ & 0.11 & $496 \dagger$ & 22.50 \\
\hline \multirow[t]{2}{*}{ TPT Warm Foot ( ${ }^{\circ} \mathrm{C}$ or \%) } & Group $1(<7 \%)$ & $0.40^{*}$ & 0.02 & $8.33^{*}$ & 0.42 \\
\hline & Group 2 ( $\geq 7 \%)$ & $5.30^{*}$ & 0.27 & $110^{*}$ & 5.50 \\
\hline \multirow[t]{2}{*}{ TPT Cold Foot ( ${ }^{\circ} \mathrm{C}$ or $\left.\%\right)$} & Group 1 (<7\%) & $0.70^{\star}$ & 0.04 & $50.0^{*}$ & 2.50 \\
\hline & Group 2 ( $\geq 7 \%)$ & $7.30^{\star}$ & 0.37 & $608^{*}$ & 30.40 \\
\hline \multirow[t]{2}{*}{ CV of HRV At rest (\% for CV or \%) } & Group $1(<7 \%)$ & -1.22 & -0.05 & -17.9 & -0.75 \\
\hline & Group $2(\geq 7 \%)$ & -2.69 & -0.11 & -46.1 & -1.92 \\
\hline \multirow{2}{*}{$\begin{array}{l}\text { CV of HRV at deep breathing } \\
\text { (\% for CV or \%) }\end{array}$} & Group $1(<7 \%)$ & $0.38 \ddagger$ & 0.02 & $3.9 \ddagger$ & 0.17 \\
\hline & Group $2(\geq 7 \%)$ & $-4.51 \ddagger$ & -0.20 & $-49.1 \ddagger$ & -2.13 \\
\hline
\end{tabular}

${ }^{*}$ Change over 20 years.

tChange over 22 years.

¥Change over 23 years.

$\mathrm{CV}$, coefficient of variation; $\mathrm{HbA1c}$, glycated haemoglobin; HRV, heart rate variability; MNCV, motor nerve conduction velocity; SNCV, sensory nerve conduction velocity; TPT, thermal perception threshold; VPT, vibration perception threshold. 
18 years of follow-up. Other reasons for drop out were inconvenience of regular follow-up and moving away from the area.

\section{DISCUSSION}

The results of this prospective study demonstrate that near-normoglycaemia maintained from the diagnosis of type 1 diabetes over the next 24 years was associated with an effective prevention of a threefold and sixfold faster annual hyperglycaemia-related decline in sural SNCV and peroneal MNCV, and preservation of NCV at the expected age-induced level of change. In poorly controlled type 1 diabetes, MNCV, SNCV and HRV started to deteriorate earlier (after approximately 4 years) than VPT and warm/cold TPT (after approximately 10-12 years), while the cumulative prevalence of confirmed clinical DSPN rose considerably from zero at diabetes diagnosis to one-third after 12 years and almost two-thirds after 24 years. In contrast, none of the patients who maintained near-normoglycaemia throughout 24 years presented with confirmed clinical DSPN after this period. Thus, the present findings are novel as they indicate that near-normoglycaemia instituted at the time of diagnosis of type 1 diabetes and subsequently maintained for more than two decades may fully prevent the development of DSPN and diminished HRV.

There are no studies with which the present data can be directly compared, since previous studies did not focus on newly diagnosed type 1 diabetes, but included patients with longer disease duration. ${ }^{3}$ 5-10 12 18-26 The EURODIAB Prospective Complications Study (PCS) and Pittsburgh Epidemiology of Diabetes Complications Study, including patients with type 1 diabetes with baseline duration of diabetes of 12.4 and 16.9 years, respectively, identified $\mathrm{HbAlc}$ as an independent predictor of incident DSPN over 7.3 and 6 years ${ }^{18} 19$ and CAN over 7.3 and 4.7 years, ${ }^{20} 21$ respectively. In newly diagnosed diabetic children followed over 10 years, a correlation between HbAlc and measures of nerve function was found for peroneal MNCV but, in contrast to the present study, not for sural SNCV nor HRV during normal and deep breathing. ${ }^{27}$ In a study of adolescents with a mean age of 15.5 years and diabetes duration of 6.8 years followed for approximately 13 years on average, HbA1c during the first year of follow-up was the strongest predictor for the development of clinical DSPN, but the rates of decline in nerve function in relation to HbAlc were not reported. ${ }^{22}$

The Oslo Study recently reported that HbA1c was an important risk factor in the development of DSPN over 27 years, but the mean diabetes duration at study start was 12.8 years, and mean HbAlc measured yearly was $8.0 \%$. Dividing patients by low-cumulative and highcumulative glycaemic exposure ${ }^{3}$ after 27 years revealed a mean decrease in peroneal MNCV of 6.7 versus $13.0 \mathrm{~m} / \mathrm{s}$ and sural SNCV of 8.1 versus $15.3 \mathrm{~m} / \mathrm{s}$, but the difference for these changes between the groups did not reach statistical significance. ${ }^{23}$ CAN was assessed at the 18-year follow-up revealing abnormalities in $\geq 2$ of 3 parameters in $29.4 \%$ of patients with mean HbAlc $<8.4 \%$ compared with $66.7 \%$ in those with mean HbAlc $\geq 8.4 \%$, but no prospective data was available. ${ }^{24}$ Likewise, in the Stockholm Diabetes Intervention Study (SDIS), including patients with type 1 diabetes with an initial mean diabetes duration of 17 years, peroneal MNCV and sural SNCV deteriorated after 10 years of IT and CT (mean HbA1c: $7.2 \%$ vs $8.3 \%$ ), albeit to a lesser degree in the IT group. ${ }^{25}$ Similar to the Oslo Study, CAN was assessed only once after 11.4 years and only three of six parameters were significantly better after IT than CT. ${ }^{26}$ Thus, in line with DCCT/EDIC, ${ }^{5} 910$ the development of DSPN and CAN in the Oslo Study and SDIS could not be entirely prevented, but only slightly delayed.

In contrast to type 1 diabetes, the role of glycaemic control in the development of DSPN in type 2 diabetes is less clear. In newly diagnosed patients with type 2 diabetes, the rates of definite or probable DSPN increased from $8.3 \%$ at baseline to $41.9 \%$ after 10 years, but mean HbA1c was not higher in patients who had DSPN at 10 years compared to those who did not $(9.6 \%$ vs $8.9 \%) .^{28}$ In patients who developed parasympathetic CAN after 10 years $(65 \%)$, HbA1c at 5 years was higher than in those who did not $(9.2 \%$ vs $8.0 \%)$, but this difference was not found for sympathetic CAN. ${ }^{29}$

The American Diabetes Association considers HbAlc levels $<7 \%$ a reasonable treatment goal for many nonpregnant adults with diabetes. More stringent HbAlc goals $(<6.5 \%)$ are suggested for selected individual patients if this can be achieved without significant hypoglycaemia or other adverse effects of treatment. ${ }^{11}$ These recommendations entirely suit the well-controlled group in the present study, which maintained mean HbAlc at $6.5 \%$.

\section{Study limitations}

The present study has some limitations. First, since this was an observational study, allocation of patients to the two groups of glycaemic control could only be done post hoc. Second, the small study sample may be a source of bias, particularly in view of the long-study duration which also inevitably resulted in some dropouts. Third, prospective assessment of neuropathy included nerve function rather than nerve structure, such as skin biopsy or corneal confocal microscopy, ${ }^{30}$ since the latter became available only recently. Nonetheless, we believe that the unequivocally preserved large and small fibre function in favour of near-normoglycaemia supports the notion that the degree of glycaemia governs the development of neuropathy over 24 years.

\section{CONCLUSIONS}

In conclusion, near-normoglycaemia maintained from the diagnosis of type 1 diabetes over the next 24 years was associated with a complete prevention of 
hyperglycaemia-induced slowing in nerve conduction, confirmed clinical DSPN, and reduced HRV. In contrast, poor glycaemic control was associated with a continuous and substantial increase in the cumulative prevalence of confirmed clinical DSPN over 24 years. Hence, poor glycaemic control constitutes the paramount causative factor contributing to the evolution of neuropathy in type 1 diabetes. The annual rates of progression of NCV, QST and HRV in well-controlled compared with poorly controlled patients may provide a rationale for the design of future long-term clinical trials aimed at prevention of diabetic neuropathy.

Acknowledgements The authors would like to acknowledge previous co-workers who were temporarily involved in various aspects of this study: F Akila, L Bansemir, K Dannehl, H Effertz-Umlauf, C Gottschalk, F A Gries, S Hilkes, A Hübinger, P Mayer, H J Mühlen, S Obst, B Pawlowski, R Piolot, A Pour Mirza, E Siekierka-Kleiser, U Sondermann, R Souren, K Wiefels, and S Witt.

Contributors DZ designed the study. DZ, MB and MS-T researched data. DZ wrote the manuscript. DZ and MR reviewed and edited the manuscript. DZ is the guarantor and as such, had full access to all of the data in the study and takes responsibility for the integrity of the data and the accuracy of the data analysis.

Funding This work was supported by the Ministry of Science and Research of the State of North Rhine-Westphalia (MIWF NRW) and the German Federal Ministry of Health (BMG).

Competing interests None declared.

Provenance and peer review Not commissioned; externally peer reviewed.

Data sharing statement No additional data are available.

Open Access This is an Open Access article distributed in accordance with the Creative Commons Attribution Non Commercial (CC BY-NC 4.0) license, which permits others to distribute, remix, adapt, build upon this work noncommercially, and license their derivative works on different terms, provided the original work is properly cited and the use is non-commercial. See: http:// creativecommons.org/licenses/by-nc/4.0/

\section{REFERENCES}

1. Boulton AJ, Vinik Al, Arezzo JC, et al. Diabetic neuropathies: a statement by the American Diabetes Association. Diabetes Care 2005;28:956-62.

2. Vinik Al, Ziegler D. Diabetic cardiovascular autonomic neuropathy. Circulation 2007;115:387-97.

3. Orchard TJ, Forrest KY, Ellis D, et al. Cumulative glycemic exposure and microvascular complications in insulin-dependent diabetes mellitus. The glycemic threshold revisited. Arch Intern Med 1997; 157:1851-6.

4. Dyck PJ, Davies JL, Clark VM, et al. Modeling chronic glycemic exposure variables as correlates and predictors of microvascular complications of diabetes. Diabetes Care 2006;29:2282-8.

5. Martin CL, Albers JW, Pop-Busui R, DCCT/EDIC Research Group. Neuropathy and related findings in the diabetes control and complications trial/epidemiology of diabetes interventions and complications study. Diabetes Care 2014;37:31-8.

6. Writing Team for the Diabetes Control and Complications Trial/ Epidemiology of Diabetes Interventions and Complications Research Group. Sustained effect of intensive treatment of type 1 diabetes mellitus on development and progression of diabetic nephropathy: the Epidemiology of Diabetes Interventions and Complications (EDIC) study. JAMA 2003;290:2159-67.

7. Pop-Busui R, Herman WH, Feldman EL, et al. DCCT and EDIC studies in type 1 diabetes: lessons for diabetic neuropathy regarding metabolic memory and natural history. Curr Diab Rep 2010:276-82.

8. Lachin JM, Genuth S, Nathan DM, et al. DCCT/EDIC Research Group. Effect of glycemic exposure on the risk of microvascular complications in the diabetes control and complications trialrevisited. Diabetes 2008;57:995-1001.

9. Albers JW, Herman WH, Pop-Busui R, et al. Effect of prior intensive insulin treatment during the Diabetes Control and Complications Trial (DCCT) on peripheral neuropathy in type 1 diabetes during the Epidemiology of Diabetes Interventions and Complications (EDIC) Study. Diabetes Care 2010;33:1090-6.

10. Pop-Busui R, Low PA, Waberski BH, et al. Effects of prior intensive insulin therapy on cardiac autonomic nervous system function in type 1 diabetes mellitus: the Diabetes Control and Complications Trial/Epidemiology of Diabetes Interventions and Complications study (DCCT/EDIC). Circulation 2009;119:2886-93.

11. American Diabetes Association. Standards of medical care in diabetes-2014. Diabetes Care 2014;37(Suppl 1):S14-80.

12. Ziegler $\mathrm{D}$, Mayer $\mathrm{P}$, Mühlen $\mathrm{H}$, et al. The natural history of somatosensory and autonomic nerve dysfunction in relation to glycaemic control during the first 5 years after diagnosis of type 1 (insulin-dependent) diabetes mellitus. Diabetologia 1991;34:822-9.

13. National Diabetes Data Group. Classification and diagnosis of diabetes mellitus and other categories of glucose intolerance. Diabetes 1979;28:1039-57.

14. Yarnitsky D, Sprecher E. Thermal testing: normative data and repeatability for various test algorithms. J Neurol Sci 1994;125:39-45.

15. Young MJ, Boulton AJ, MacLeod AF, et al. A multicentre study of the prevalence of diabetic peripheral neuropathy in the United Kingdom hospital clinic population. Diabetologia 1993;36:150-4.

16. Ziegler D, Laux G, Dannehl K, et al. Assessment of cardiovascular autonomic function: age-related normal ranges and reproducibility of spectral analysis, vector analysis, and standard tests of heart rate variation and blood pressure responses. Diabet Med 1992:9:166-75.

17. Gleichmann H, Zörcher B, Greulich B, et al. Correlation of islet cell antibodies and HLA-DR phenotypes with diabetes mellitus in adults. Diabetologia 1984;27(Suppl):90-2.

18. Tesfaye S, Chaturvedi N, Eaton SE, et al. Vascular risk factors and diabetic neuropathy. N Engl J Med 2005;352:341-50.

19. Forrest KY, Maser RE, Pambianco G, et al. Hypertension as a risk factor for diabetic neuropathy: a prospective study. Diabetes 1997:46:665-70.

20. Witte DR, Tesfaye S, Chaturvedi N, et al. Risk factors for cardiac autonomic neuropathy in type 1 diabetes mellitus. Diabetologia 2005;48:164-71.

21. Stella $P$, Ellis D, Maser RE, et al. Cardiovascular autonomic neuropathy (expiration and inspiration ratio) in type 1 diabetes. Incidence and predictors. J Diabetes Complications 2000;14:1-6.

22. Hyllienmark L, Alstrand N, Jonsson B, et al. Early electrophysiological abnormalities and clinical neuropathy: a prospective study in patients with type 1 diabetes. Diabetes Care 2013:36:3187-94.

23. Sveen KA, Karimé B, Jørum E, et al. Small- and large-fiber neuropathy after 40 years of type 1 diabetes: associations with glycemic control and advanced protein glycation: the Oslo Study. Diabetes Care 2013;36:3712-17.

24. Larsen JR, Sjoholm H, Hanssen KF, et al. Optimal blood glucose control during 18 years preserves peripheral nerve function in patients with 30 years' duration of type 1 diabetes. Diabetes Care 2003;26:2400-4.

25. Reichard $\mathrm{P}, \mathrm{Pihl} \mathrm{M}$, Rosenqvist $\mathrm{U}$, et al. Complications in IDDM are caused by elevated blood glucose level: the Stockholm Diabetes Intervention Study (SDIS) at 10-year follow up. Diabetologia 1996;39:1483-8.

26. Reichard $\mathrm{P}$, Jensen-Urstad K, Ericsson $\mathrm{M}$, et al. Autonomic neuropathy-a complication less pronounced in patients with type 1 diabetes mellitus who have lower blood glucose levels. Diabet Med 2000;17:860-6.

27. Solders G, Thalme B, Aguirre-Aquino M, et al. Nerve conduction and autonomic nerve function in diabetic children. A 10-year follow-up study. Acta Paediatr 1997;86:361-6.

28. Partanen J, Niskanen L, Lehtinen J, et al. Natural history of peripheral neuropathy in patients with non-insulin-dependent diabetes mellitus. N Engl J Med 1995;333:89-94.

29. Töyry JP, Niskanen LK, Mäntysaari MJ, et al. Occurrence, predictors, and clinical significance of autonomic neuropathy in NIDDM. Ten-year follow-up from the diagnosis. Diabetes 1996;45:308-15.

30. Ziegler D, Papanas N, Zhivov A, et al. Early detection of nerve fiber loss by corneal confocal microscopy and skin biopsy in recently diagnosed type 2 diabetes. Diabetes 2014;63:2454-63. 